\title{
Internal Quality Audit In The Implementation Of Quality Assurance System Of Continuining Education At Junior High School
}

\author{
Amiruddin \\ Universitas Negeri Surabaya \\ Surabaya, Indonesia \\ limbitubima@gmail.com
}

\begin{abstract}
The objectives of the study were (1) to examine the validity level of content and constructs of the internal quality audit model and internal quality audit tools used in the internal audit quality activity in the internal quality monitoring system, (2) to examine the practicality level of the internal quality audit model developed and used in the implementation the internal quality assurance system (3) examines the effectiveness of the internal audit quality model developed in achieving the objectives of the internal quality audit. This study is a research and development that is adapted from Plomp and Nieveen with three stages, namely: preliminary study, prototyping, and assessment of model.

The study involved five experts and practitioners to become expert reviews to assess the validity and reliability of the model. Limited trials of AMI-S model implementation were implemented in one school based on SPMI model. Extensive trials of AMI-S model implementation were implemented in three SPMI model-based schools. Experiment test data and expert test data were analyzed using single measure inter-rater coefficient correlation ( $\left.r \_a\right)$ and Cronbach's alpha $(\alpha)$

The results showed that the validity of AMI-S model contents reached $r_{a}=0.971$ and $\alpha=0.994$ while the validity of the construct reached $r_{\mathrm{a}}=0.967$ and $\alpha=0.993$ so that the AMI-S model qualified valid and reliable model. The practicality of the AMI-S model's luminance aspect reaches $r_{\mathrm{a}}=0.9993$ and $\alpha=$ 1,000 , and the practicality of convenience, simplicity and functionality reaches $r_{a}=0.8776$ and $\alpha=0.9847$, so the AMI-S model includes a practical model. The effectiveness of the AMI-S model on the measurement shows $r_{a}=0.9579$ and $a=0.9951$, so the AMI-S model includes an effective model.
\end{abstract}

Keywords-Internal Quality Audit; SPMI, AMI-S Model; Validity and Reliability Model AMI-S; Practicality of AMI-S model; effectiveness of AMI-S model

\section{INTRODUCTION}

Quality assurance is done to ensure that the quality of education offered can be achieved. Therefore, the quality assurance activities of education should be viewed as a management cycle in the implementation of education which includes measuring, evaluating, and guarding the quality of academic and non-academic practice and tradition in the education unit.
So the quality of education as the best form generated by the educational process in the educational unit can be achieved.

Quality assurance of education is important to monitor and ensure that every program and activity in the educational unit is organized according to the quality standard of education. Quality assurance education does not have to wait for other parties outside the educational unit to implement it. Quality assurance conducted internally by educational unit will be more efficient and can measure gradually the quality achievement that has been, is and will be achieved. The basis of the achievement of education quality by education unit internally can refer to the National Education Standards that have been issued by the government. With the formation of quality assurance at the school level, the internalization of quality in all activities can be realized. It is important for schools to plan and move towards an advantage. This confirms that quality is not a static phenomenon, but a dynamic one, and the targets of excellence are also always on the move.

National Education Standards are the minimum criteria on the implementation of the education system applied to all educational units that are in the jurisdiction of the Unitary State of the Republic of Indonesia. National Education Standards serve as a foundation in the planning, implementation, and supervision of education in order to realize a quality national education.

Quality assurance of education should be done gradually, systematically, and planned in the form of quality assurance program with clear target and time frame. This indicates that the quality assurance of education is an activity that has a continuous and continuous cycle. The intended cycle is "Planning, Do, Check, and Action" (PDCA). The cycle popularized by Deming illustrates that the overall quality will begin by planning, executing, evaluating and ending with follow up. So that there will be continuous improvement that leads to improving the quality of education. 


\section{RESEARCH METHODS}

\section{A. Types Methods}

The research design used in this AMI-S model research is the development research design, the research and development design that comes from the Plomp and Nieveen research stages [1], which include: Preliminary research stage, prototyping stage), and the assessment stage.

\section{B. Research sites}

Limited trials conducted in SMP Negeri 2 Lamongan. The schedule for the implementation of the limited trial is conducted in December 2017 until January 2018. While the broad test is conducted in SMPN 1 Karang Geneng Lamongan, SMPN 1 Babat Lamongan, and SMPN 1 Kedungpring Lamongan. The extensive test schedule is held in February 2018 until March 2018.

\section{Trial Design}

Expert testing by Plomp [2] is referred to as expert test or expert judgement. The purpose of expert test or expert jugdgement in this research is to know the validity level of the internal quality audit model and the supporting tool for the implementation of the developed audit model. Assessment of validity level is done by requesting consideration to the expert about the contents, advance and logic of all draft product I. The instrument used is validation sheet of internal quality audit model and the device. The instrument is firstly tested for eligibility on the instrument feasibility test.

The result of the development of draft model I which has been declared valid by the experts is the product of draft II. The draft II product will be used in field trials. Field trials were conducted in the form of limited trials and extensive trials. Limited trials are intended to see the practicality and effectiveness of product implementation developed prior to extensive testing. Extensive trials are conducted to determine the final product of the internal quality audit model.

\section{Methods and Instrument Research}

The instruments used in Preliminary Research are interview guides, observation guidelines, and documentation. The validity assessment instrument in this research is named validation sheet, the instrument used by the validator to assess the validity of the model that has been developed. The validity sheet consists of: model validity sheet and validity of AMI-S model support device. The instrument developed for testing is an instrument used to view the implementation or application of an AMI-S model. This instrument consists of the practicality, effectiveness and implementation of the AMI-S model.

\section{DATA ANALYSIS}

Data analysis in this study using qualitative and quantitative analysis approach, because the data obtained in the form of qualitative and quantitative data. Data analysis used in this research are: (1) Analysis of instrument feasibility data, (2) data analysis at preliminary study stage, (2) data analysis at model development stage, and (3) data analysis at model validation stage.

Instrument feasibility can be measured from the validity of the content of the validity of the display or face validity and logical validity or logical validity (Allen \& Yen, 1979). Logical validity is obtained through examination of the instrument items to make the conclusion that the instrument measures the relevant aspects. One of the recommended approaches for evaluating instrument items has content validity is the content validity index (CVI). Calculating CVI according to Lynn [3] in his research was conducted in two types of content validity. The first type involves the validity of the contents of individual items (i-CVI) and the second type involves the validity of the content of the overall scale (s-CVI). In this study used CVI first type, namely i-CVI. Polit and Beck [4] recommend an I-CVI value of 0.80 while Lynn [3] is 0.78 . The successfully developed AMI-S Model products consist of AMI-S model books and AMI-S model devices. The AMI-S model device consists of Quality standards, standard operating procedures, internal quality audit guidelines, and forms and audit forms. Validation of AMI-S model through AMI-S model book and its equipment is done by experts who are experts in their respective fields. While the examination is assessed by practitioners. The calculation of the validity and reliability of the AMI-S model, the validity and reliability of AMI-S model devices, the practicality, effectiveness and effectiveness of the AMI-S model were analyzed using interrater correlation coefficient and cronbac alpha [5].

$$
\begin{gathered}
r_{a}=\frac{M S \text { people }-M S \text { residual }}{M S \text { people }+(k-1) M S \text { residual and }} \\
a=\frac{k r a}{l+(k-1) r a}
\end{gathered}
$$

Where MS $=$ Mean suqare, $k=$ number of item

Criteria of Validity and Reliability Model AMI-S and its

\begin{tabular}{|c|c|c|c|c|}
\hline No. & $\begin{array}{c}\text { Assesm } \\
\text { ent }\end{array}$ & $\begin{array}{c}\text { Scale } \\
\text { Statistics }\end{array}$ & Criteria & $\begin{array}{l}\text { Categor } \\
\mathrm{y}\end{array}$ \\
\hline \multirow[t]{2}{*}{1} & \multirow[t]{2}{*}{$\begin{array}{l}\text { Validit } \\
\text { y }\left(\boldsymbol{r}_{\boldsymbol{a}}\right)\end{array}$} & \multirow[t]{2}{*}{$\begin{array}{l}\text { Singel } \\
\text { Measure } \\
\text { s ICC }\end{array}$} & $\underset{\text { tabel }}{\boldsymbol{r}_{\boldsymbol{a}}} \leq \mathrm{r}$ & Invalid \\
\hline & & & $\underset{\text { tabel }}{\boldsymbol{r}_{\boldsymbol{a}}}>\mathrm{r}$ & Valid \\
\hline \multirow[t]{2}{*}{2} & \multirow[t]{2}{*}{$\begin{array}{l}\text { Reliabi } \\
\text { lity }(\alpha)\end{array}$} & \multirow{2}{*}{$\begin{array}{l}\text { Cronbac } \\
h \text { 's } \\
\text { Alpha/Av } \\
\text { erage } \\
\text { Measure } \\
\text { s ICC }\end{array}$} & $\alpha<0,6$ & $\begin{array}{l}\text { Not } \\
\text { Reliabl } \\
\mathrm{e}\end{array}$ \\
\hline & & & $\begin{array}{l}0,6 \geq \alpha \geq \\
1.0\end{array}$ & $\begin{array}{l}\text { Reliabl } \\
\text { e }\end{array}$ \\
\hline
\end{tabular}
devices. 

results

Description $\Gamma_{n}=$ validity test results, $\alpha=$ reliability test

The implementation data of the AMI-S model consists of the implementation of the model steps, the implementation of the social system, the implementation of performance, practicality and effectiveness of the AMI-S model is also processed by qualitative descriptive method using the following equation.

$p=\frac{\text { AMI stage Implementation }}{\text { Total of Audit Stage }} \times 100 \%$

Description:

$\mathrm{P}=$ Percentage of AMI-S model implementation

\section{A. AMI-S Model Validation Results}

The contents of the AMI-S model have a high validity and reliability value that is the correlation coefficient between rater (validator) on single measurement (Single Measure ICC) of $r_{a}=0.971>0.754(r$ table) and Cronbach's Alpha or Average Measures ICC $(\alpha)$ of $0.994>0.60$. The construct of AMI-S model has a high validity and reliability value which is the correlation coefficient between rater (validator) on single measurement (Single Measure ICC) of $r_{a}=0.967>0.754(r$ table) and Cronbach's Alpha or Average Measures ICC $(\alpha)$ its 0.993 $>0.60$.

A good model must meet the valid requirements of content and constructs. Content validity refers to the level of intervention design based on state-of-the art knowledge [1]. Whereas construct validity refers to a consistent linkage between all component models [1]. To determine the level of content and construct validity, validity test involves several experts and practitioners named by Richey [7] and Plomp [1] as expert review or expert judgments approach in determining the validity of the model.

According to the validators involved as an expert review that the AMI-S model design has high validity and reliability values both in content and construct aspects. The contents of the AMI-S model include the rationale of AMI$\mathrm{S}$ model development, relevant to the latest state of the art of knowledge, theoretical and empirical support of the AMI-S model, AMI-S model description, audit environment and School management. The high reliability value illustrates that the AMI-S model has been stable and can be used in the implementation of internal quality audits at schools. One rational development of AMI-S model is directed to facilitate the implementation of quality audits conducted internal in schools in the implementation of internal quality assurance system.

The model construct consisting of the suitability of the AMI-S model with the needs, theoretical and empirical support of the AMI-S model, the model steps, the social system, the communication principles, and the AMI-S model support system have met the valid and reliable criteria. The suitability of the AMI-S model with needs is based on the needs of the model schools implementing internal quality monitoring system called SPMI, particularly the demands of the implementation cycle of the internal quality assurance system related to the evaluation of quality fulfillment and compliance with new quality standards.

\section{B. Device Model Validation Results AMI-S}

Generally all AMI-S model support devices have high validity and reliability values. As the following table shows.

\begin{tabular}{|l|c|c|c|}
\hline \multirow{2}{*}{$\begin{array}{c}\text { Device } \\
\text { Type }\end{array}$} & \multicolumn{2}{|c|}{ Measurement results } & \multirow{2}{*}{ Category } \\
\cline { 2 - 3 } & $\begin{array}{c}\text { Singel } \\
\text { Measures } \\
\text { ICC }\left(\boldsymbol{r}_{\boldsymbol{\alpha}}\right)\end{array}$ & $\begin{array}{c}\text { Cronbach's } \\
\text { Alpha }(\alpha)\end{array}$ & \\
\hline $\begin{array}{l}\text { Quality } \\
\text { Standard }\end{array}$ & $\begin{array}{c}0.9353>0 . \\
7540\left(\mathrm{r}_{\text {tabel }}\right)\end{array}$ & $\begin{array}{c}0.9863> \\
0.60\end{array}$ & $\begin{array}{c}\text { Valid and } \\
\text { reliable }\end{array}$ \\
\hline $\begin{array}{l}\text { Quality } \\
\text { Procedure }\end{array}$ & $\begin{array}{c}0.9741>0 . \\
7540\left(\mathrm{r}_{\text {tabel }}\right)\end{array}$ & $\begin{array}{c}0.9957> \\
0.60\end{array}$ & $\begin{array}{c}\text { Valid and } \\
\text { reliable }\end{array}$ \\
\hline $\begin{array}{l}\text { Audit } \\
\text { Guidelines }\end{array}$ & $\begin{array}{c}0.9769>0 . \\
7540\left(\mathrm{r}_{\text {tabel }}\right)\end{array}$ & $\begin{array}{c}0.9952> \\
0.60\end{array}$ & $\begin{array}{c}\text { Valid and } \\
\text { reliable }\end{array}$ \\
\hline $\begin{array}{l}\text { Form and } \\
\text { Form }\end{array}$ & $\begin{array}{c}0.9518>0 . \\
7540\left(\mathrm{r}_{\text {tabel }}\right)\end{array}$ & $0.9899>$ & 0.60 \\
\hline
\end{tabular}

The method used to assess the validity of the AMI-S model device is the same as the method for assessing the validity of the AMI-S model design, the expert review. AMI-S model devices reviewed by experts and practitioners include: quality standards, quality procedures, internal quality audit guidelines, and forms and / or forms. All devices supporting AMI-S models include devices that meet valid and reliable requirements.

The development of AMI-S model device in the form of quality standard is based on the idea that the implementation of internal quality audit is part of the activity of the internal quality assurance system in the school. Internal quality assurance system is a process of compiling, determining, and fulfilling quality standard performed consistently and continuously by the school internally [8]. The established quality standards serve as a guideline for internal assessments by institutions (Cassagne and Dhainaut: 2006). Internal assessments made through internal audit processes by Ridley $\mathrm{J}$ [9] are part of a continuous process of monitoring quality performance standards to ensure adequate performance.

Standard Operating Procedures (POS) are structured to facilitate the implementation of operational quality standards in schools. The implementation of quality standards in schools is integrated into each unit or section according to the school's organizational structure. The POS function constructed in the implementation of the AMI-S model is as a reference used by the internal auditor in examining and assessing the suitability of the quality documents in each of the audited fields. The determination of conformity is based on the extent to which compliance and / or compliance of the system or process 
against defined audit criteria. Audit Criteria according to ANSI / ISO / ASQ QE19011S) and ANSI / ISO / ASQ Q9000 relate to internal documents such as procedures or work instructions or external documents referred to by the institution. The compiled POS has characteristics relevant to the rule of law, has a POS inter-orientation, user-oriented, systematic display or presentation, measurable or declared desired result specification, ensures efficiency and effectiveness, and clarity of formulation.

The quality audit guidelines developed are structured according to the needs and scope of internal quality audits applicable at junior high school. Ruud [10] states that the powers and responsibilities of internal audit activities should be formally defined in a guidelines (charter) and approved by the board. The British Standard [11] proposes seven components to the existing audit guidelines: scope, normative references, terms and definitions, audit principles, managing audit programs, auditing, and auditor competence and evaluation. The components of the AMI-S model quality audit guidelines are prepared based on the need for internal quality audits at schools.

Assessment of forms and forms has a high value of validity and reliability. The forms and forms developed for the implementation of the AMI-S model have several functions as outlined by the SPMI-PT Developer Team (2010), namely (1) assisting with the control of the audit implementation (2) minimizing data presentation errors (3) identifying and documenting the findings (5) providing evidence support (6) providing evidence support for inspection reports, (7) as a tool for supervisors or team leaders to review checkup result.

\section{Trial Results Model AMI-S}

The limited test results and extensive test of AMI-S model indicate that all aspects of AMI-S model implementation consist of supporting system, social system, AMI-S model steps, and communication system can be implemented very well is $91.66 \%$. The correlation coefficient between auditor in assessing the practicality of AMI-S model on single measurement (Single Measure ICC) is very high, that is $r_{a}=$ 0.9894.. Thus, also with reliability value (Average Measures ICC) practicality of AMI-S model is very high that is a = 0.9964. The effectiveness of AMI-S model also shows very high result that is $r_{a}=1.000$ and $a=1.000$.

AMI-S model test results show that the auditor evaluates AMI-S model including practical model because all aspects of practicality assessment reach $89.63 \%$. The correlation coefficient among auditors in assessing the practicality of AMI-S model in Single Measure-ICC is also high, that is $r_{-} a=$ 0.8776 . Thus, also with reliability value (Average Measures ICC) practicality of AMI-S model is very high $(\mathrm{a}=0.9847)$..

The results of extensive AMI-S model test on the effectiveness aspect also showed a consistent result that is the effectiveness value of $98 \%$. The correlation coefficient between auditors in assessing the effectiveness of AMI-S model on single measurement (Single Measure-ICC) is very high, that is $r_{a}=0.9579$. Thereby also with the reliability value (Average Measures ICC) the effectiveness of AMI-S model is very high that is $\mathrm{a}=0.9951$.

\section{CONCLUSION}

Based on AMI-S models, limited AMI-S model trials, and extensive AMI-S model trials can be summarized below.

a. The internal quality assurance system cycles undertaken in junior secondary school consist of: quality mapping, quality pact plan, quality fulfillment, quality assurance monitoring, internal quality audit, and new quality standards

b. The AMI-S model cycle in the implementation of the internal quality monitoring system at the school consists of: preparation of an internal quality monitoring system, internal quality audit implementation, corrective action requests and reporting, and evaluation of the implementation of internal quality audits.

c. The AMI-S model developed in this study belongs to a valid category of content and is constructed constructally and reliably both internally, between rater (assessors), and measurement

d. The AMI-S model support devices consisting of quality standard books, quality procedures, audit guidelines, and internal quality audit form and form are categorized as valid content and reliably both internally, between rater (assessors) and measurement.

e. The implementation of the AMI-S model demonstrates that all components of the AMI-S model consisting of AMI-S model steps, social systems, communication principles and support systems can be implemented very well.

f. The AMI-S model has an excellent level of practicality so that it has a simple or uncomplicated nature, is easy to use and works well for conducting internal quality audits.

g. The AMI-S model is very effective in achieving internal quality audit objectives in the implementation of internal quality assurance system in junior high school.

\section{REFERENCES}

[1] T. Plomp and N. Nieveen, "An introduction to educational design research," in Proceedings of the seminar conducted at the East China Normal University, Shanghai (PR China), 2007, pp. 23-26.

[2] T. Plomp, "Educational design research: An introduction," Educ. Des. Res., pp. 11-50, 2013.

[3] M. R. Lynn, "Determination and quantification of content validity.," Nurs. Res., 1986.

[4] D. F. Polit and C. T. Beck, "The content validity index: are you sure you know what's being reported? Critique and recommendations," Res. Nurs. Health, vol. 29, no. 5, pp. 489-497, 2006.

[5] N. L. Leech, K. C. Barrett, and A. George, "Morgan. 2005. SPSS for Intermediate Statistics: Use and Interpretation." Mahwah, NJ: Lawrence Erlbaum Associates.

[6] N. L. Leech, K. C. Barrett, and A. George, "Morgan (2005)," SPSS Intermed. Stat. Use Interpret. 
[7] R. C. Richey and J. D. Klein, "Developmental research methods: Creating knowledge from instructional design and development practice," J. Comput. High. Educ., vol. 16, no. 2, pp. 23-38, 2005.

[8] F. E. Daromes and S. Ng, "Embedding core value into the internal quality assurance systems in higher education," Procedia-Social Behav. Sci., vol. 211, pp. 660-664, 2015.
[9] J. Ridley and J. Channing, Safety at work. Routledge, 2008.

[10] T. F. Ruud, "The internal audit function: An integral part of organizational governance," Res. Oppor. Intern. Audit., pp. 73-96, 2003.

[11] B. Standard, Guidelines for auditing management systems. England: BSI, 2011. 